\title{
Evaluation of drug promotional literatures in a tertiary care hospital setting in South India
}

\author{
Ravi H. Kudthni ${ }^{1}$, Fazeel Zubair Ahmed ${ }^{2 *}$, Sangala Srimanth Madanna ${ }^{1}$, \\ Samba Siva Raju Derangula ${ }^{1}$, Pothuru Anil Kumar ${ }^{1}$
}

\author{
${ }^{1}$ Department of Pharmacology, Viswabharathi Medical College, Kurnool, Andhra Pradesh, India \\ ${ }^{2}$ Department of Pharmacology, Malla Reddy Medical College for Women, Hyderabad, Telangana, India
}

Received: 04 March 2021

Revised: 08 April 2021

Accepted: 09 April 2021

\section{*Correspondence:}

Dr. Fazeel Zubair Ahmed,

Email: fazeelzubair@yahoo.com

Copyright: (c) the author(s), publisher and licensee Medip Academy. This is an open-access article distributed under the terms of the Creative Commons Attribution Non-Commercial License, which permits unrestricted non-commercial use, distribution, and reproduction in any medium, provided the original work is properly cited.

\begin{abstract}
Background: The drug promotional literature is one of many sources for seeking information about the drugs to the busy medical practitioner. The aim of current study was to assess drug promotional literatures as per world health organization, criteria and categorize them and to analyse the claims in presented in DPL.

Methods: Current study is a descriptive study in which pharmaceutical promotional materials were collected from selected out-patient departments of a tertiary care hospital, Kurnool. Printed drug promotional literatures for modern drugs were collected and an assessment was made whether the advertisements adhered to WHO criteria for medicinal drug promotion.

Results: A total of $271 \mathrm{drug}$ promotional literatures were collected. Information about the single drug was given in 127 (46.9\%). 144 (53.1\%) DPLs contain fixed-dose combination. Majority of drug promoted in collected DPLs were miscellaneous group $83(30.8 \%)$ followed by antimicrobials 55(20.3\%) and blood and cardiovascular drugs 37(13.1), gastrointestinal drugs 23(8.5\%), drugs acting on endocrine system 23(84.5\%). Generic name was mentioned in $229(84.5 \%)$ while brand name was mentioned in $271(100 \%)$ of DPL.

Conclusions: The study concluded that the drug information provided in the promotional brochures can be incomplete and unreliable. Hence a physician should not rely solely on the DPL provided by medical representatives. All brochures circulated among prescribers must undergo a strict process of assessment regarding information provided, especially related to efficacy and safety.
\end{abstract}

Keywords: WHO guidelines, Drug promotional literature, Tertiary care hospital

\section{INTRODUCTION}

In recent decades there is a rapid rise of drug companies not only in western countries but also in Asia particularly India. All these pharmaceutical companies want their products to reach every corner of world. In this connection they want to promote their pharmaceutical product to each and every prescriber. They promote their product to physician either verbal, written or by meeting them professionally, advertising in journal. They also employ medical representatives for this purpose. They spend lot of money for having effective communication to physician while promoting their product.

WHO expert committee has put forward certain criteria to be followed by people in all walks of life; by governments; the pharmaceutical industry; the promotion 
industry; health personnel involved in the prescription, dispensing, supply and distribution of drugs; universities and other teaching institutions; professional associations; patients' and consumer groups; and the professional and general media.

A "pharmaceutical product" means all pharmaceutical or biological products which are intended to be used on the prescription of, or under the supervision of, a healthcare professional, and which are intended for use in the diagnosis, treatment or prevention of disease in humans, or to affect the structure or any function of the human body. The word "promotion" means any activity undertaken, organized or sponsored by a member company which is directed at healthcare professionals to promote the prescription, recommendation, supply, administration or consumption of its pharmaceutical product(s) through all methods of communications, including the internet. One of the well-known promotional activities of pharmaceutical industries is to produce advertising brochures and leaflets. ${ }^{1}$

The literature promoting the drugs and devices are distributed by the drug company representative to physicians. This drug promotional literature (DPL) is one of many sources for seeking information about the drugs to the busy medical practitioner. Physicians can get information about the drugs from text books, journals, internet and attending continued medical education, national and international conferences. ${ }^{2,3}$

There is a huge monetary involvement in drug promotion. A study suggests that the amount of money involved in drug promotion by the manufacturers is at least 30 times more than the money spent on drug information by the government. ${ }^{4}$ As there is an aggressive drug promotion by all companies the possibility of promotion being unethical is also high. Moreover, the information provided by the medical representatives is the only source of information about the medicine in developing countries. ${ }^{5}$ Studies also suggest that promotion affects attitudes and behaviour. ${ }^{6}$

It is necessary that the promotional literature presenting the research findings should provide all information. A physician is required to know how to utilise new drugs and also how to analyse research findings and draw conclusions as misleading and wrong information is common in the literature used for drug promotion. Sometimes such literatures are inaccurate and are of poor educational value that may lead to prescribing of more expensive products where cheaper alternatives are available.

This may also lead to patient suffering unnecessary adverse effects. These promotional activities create the potential for inappropriate prescribing practices by influencing physicians' prescribing behaviour without necessarily benefiting the patients but contribute to increased health carecosts. ${ }^{7,8}$ Therefore the information available to prescriber should be authentic, unbiased and complete in order to help him to select and use the drug appropriately in a given patient. ${ }^{9}$

Pharmaceutical companies are supposed to follow the ethical guidelines for drug promotional activities. At the international level, there are two main guidelines in existence. One is "ethical criteria for medicinal drug promotion" recommended by world health organization (WHO), 1988 and the other one is the code of pharmaceutical marketing practices recommended by international federation of pharmaceutical manufacturers and associations (IFPMA). ${ }^{1,10}$ In India, such guidelines are formulated and implemented by organization of pharmaceutical producers of India (OPPI $)^{11}$ which are in line with WHO recommendations.

Current research was conducted to evaluate the drug promotional literatures whether the information provided in those were accurate, consistent and valid or not.

\section{Objectives}

Objective of current study were to evaluate and analyse the drug promotional literature distributed by pharmaceutical companies to physicians using world health organization (WHO) criteria for ethical medicinal drug promotion also to categorize and analyse the claims in presented in DPL.

\section{METHODS}

Present study was a descriptive study. Pharmaceutical promotional materials were collected from selected outpatient departments of Viswabharathi medical college and general hospital, Penchikalapadu, Kurnool between September to November 2020. Printed drug promotional literatures for modern drugs were collected as per selection criteria and analysed.

\section{Exclusion criteria}

Exclusion criteria for current study were; DPLs promoting drugs other than allopathic drugs, promotional literature other than full advertisement and DPL of medicinal devices and equipment.

An assessment was made of whether the advertisements adhered to WHO criteria for medicinal drug promotion. WHO criteria for fulfilment of each of the following parameters; the approved generic name of the drug, the brand name, the content of active ingredient per dosage, form or regimen, name of other ingredients known to cause problems, approved therapeutic uses, dosage form or regimen, side-effects, precautions, contra-indications, and warnings, major interactions, name and address of manufacturer or distributor and reference to scientific literature. In addition to fulfilment of the "WHO criteria" types of claims and pictorial content presented in DPLs were also evaluated. Claims made in the promotional 
brochures were classified into following categories; efficacy, pharmacokinetic property, pharmaceutical property, safety, cost, first time, novel, purest of choice etc.

\section{Study design, sample size and sampling method}

Current study was a descriptive study wherein the sample size was calculated using study Pradnya Deolekaret al method with $95 \%$ confidence level and absolute allowable error of $6 \% .{ }^{12}$ As per calculation minimum of 216 samples should be included in the study. A nonprobability sampling technique i.e., a purposive convenience sampling method was used in current investigation.

\section{Statistical analysis}

All the data collected are entered and compiled into a Microsoft excel worksheet. Descriptive statistics number and percentages are calculated. The data were analysed using statistical software's SPSS 20.

\section{RESULTS}

A total of 271 drug promotional literatures were collected. Information about the single drug was given in 127 (46.9\%). 144 (53.1\%) DPLs contain fixed-dose combination (Table 1).

Table 1: Type of drug.

\begin{tabular}{|lll|}
\hline Type of drug & N & $\%$ \\
\hline Single & 127 & 46.9 \\
\hline FDC & 144 & 53.1 \\
\hline Total & 271 & 100.0 \\
\hline
\end{tabular}

Majority of drug promoted in collected DPLs were miscellaneous group $83 \quad(30.8 \%)$ followed by
Antimicrobials 55(20.3\%) and blood and cardiovascular drugs 37(13.1), gastrointestinal drugs 23(8.5\%), drugs acting on endocrine system 23(8.5\%) (Table 2).

Generic name was mentioned in $229(84.5 \%)$ while brand name was mentioned in $271(100 \%)$ of DPL. The content of active ingredient per dosage was noted in $208(76.8 \%)$. Approved therapeutic uses mentioned in 159 (58.7\%) and in $95(35.1 \%)$ it was incomplete. Similarly, dosage form or regimen was noted in $86(31.7 \%)$ and in $69(25.5 \%)$ DPL it was incomplete. Side effects and major adverse drug reactions were seen in $32(11.8 \%)$ DPL, precautions, contra-indications and warnings in 32 (11.8\%) DPL, major interactions in $31(11.4 \%)$ DPL. Likewise name and address of manufacturer or distributor noted in 227 $(83.8 \%)$ and reference to scientific literature as appropriate 117 (43.2\%) DPLs (Table 3, Figure 1).

Claims were also categorized, most of the claims were based on efficacy 107 (39.5\%), pharmaceutical property $75(27.7 \%)$ followed by pharmacokinetic property 51 (18.8\%) (Table 4).

Table 2: Which group does it belong to?

\begin{tabular}{|lll|}
\hline Which group does it belong to & N & $\%$ \\
\hline Antimicrobials & 55 & 20.3 \\
\hline Blood and cardiovascular drugs & 37 & 13.7 \\
\hline Anti-inflammatory drugs & 11 & 4.1 \\
\hline Gastrointestinal drugs & 23 & 8.5 \\
\hline Drug used in gynaecology & 2 & 0.7 \\
\hline Antihistaminics & 11 & 4.1 \\
\hline $\begin{array}{l}\text { Drugs used in respiratory tract } \\
\text { system }\end{array}$ & 3 & 1.1 \\
\hline Drugs used in CNS & 14 & 5.2 \\
\hline Drugs used in endocrinology & 23 & 8.5 \\
\hline Ophthalmic drugs & 9 & 3.3 \\
\hline Miscellaneous & 83 & 30.6 \\
\hline Total & 271 & 100.0 \\
\hline
\end{tabular}

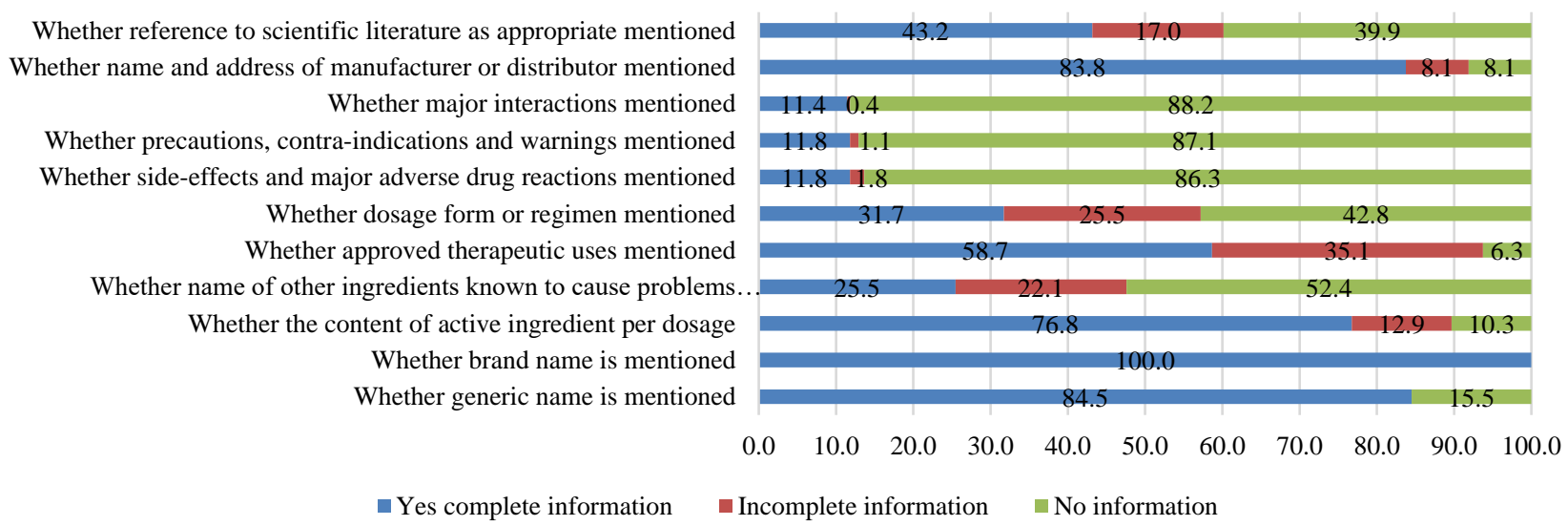

Figure 1: WHO criteria fulfilment. 


\section{DISCUSSION}

Printed promotional literatures are easily available, accessible and important source of drug information. Every year a number of new drugs and old drugs with new uses, dosage forms are entering into the Indian market. In the present study, brand name was mentioned in all $271(100 \%)$ promotional literature like previous studies and generic name in $229(84.5 \%) .{ }^{13}$ In current study the active ingredient per dosage was mentioned in 208 (76.8) while in $35(12.9 \%)$ it was incomplete and in 28 (10.3) DPL it was not mentioned. In 142 (52.4\%) DPL there was no mention of other ingredients known to cause problems. Approved therapeutic uses mentioned was noticed in $159(58.7 \%)$, in $95(35.1 \%)$ it was incomplete and in $17(6.3 \%)$ there was no mention at all.

Table 3: WHO criteria fulfilment.

\begin{tabular}{|c|c|c|c|c|c|c|}
\hline \multirow[t]{2}{*}{ WHO criteria } & \multicolumn{2}{|c|}{$\begin{array}{l}\text { Yes, } \\
\text { complete } \\
\text { information }\end{array}$} & \multicolumn{2}{|c|}{$\begin{array}{l}\text { Incomplete } \\
\text { information }\end{array}$} & \multicolumn{2}{|c|}{$\begin{array}{l}\text { No } \\
\text { information }\end{array}$} \\
\hline & $\mathbf{N}$ & $\%$ & $\mathbf{N}$ & $\%$ & $\mathbf{N}$ & $\%$ \\
\hline Whether generic name is mentioned & 229 & 84.5 & 0 & 0.0 & 42 & 15.5 \\
\hline Whether brand name is mentioned & 271 & 100.0 & 0 & 0.0 & 0 & 0.0 \\
\hline Whether the content of active ingredient per dosage & 208 & 76.8 & 35 & 12.9 & 28 & 10.3 \\
\hline $\begin{array}{l}\text { Whether name of other ingredients known to cause problems } \\
\text { mentioned }\end{array}$ & 69 & 25.5 & 60 & 22.1 & 142 & 52.4 \\
\hline Whether approved therapeutic uses mentioned & 159 & 58.7 & 95 & 35.1 & 17 & 6.3 \\
\hline Whether dosage form or regimen mentioned & 86 & 31.7 & 69 & 25.5 & 116 & 42.8 \\
\hline Whether side-effects and major adverse drug reactions mentioned & 32 & 11.8 & 5 & 1.8 & 234 & 86.3 \\
\hline Whether precautions, contra-indications and warnings mentioned & 32 & 11.8 & 3 & 1.1 & 236 & 87.1 \\
\hline Whether major interactions mentioned & 31 & 11.4 & 1 & 0.4 & 239 & 88.2 \\
\hline $\begin{array}{l}\text { Whether name and address of manufacturer or distributor } \\
\text { mentioned }\end{array}$ & 227 & 83.8 & 22 & 8.1 & 22 & 8.1 \\
\hline Whether reference to scientific literature as appropriate mentioned & 117 & 43.2 & 46 & 17.0 & 108 & 39.9 \\
\hline
\end{tabular}

Table 4: Classification of claims made in drug promotional literatures.

\begin{tabular}{|c|c|c|}
\hline Classification of claims & $\mathbf{N}$ & $\%$ \\
\hline Anti-couterfeit & 1 & 0.4 \\
\hline Clinically proven & 1 & 0.4 \\
\hline Compiance & 1 & 0.4 \\
\hline Cost & 18 & 6.6 \\
\hline Efficacy & 107 & 39.5 \\
\hline First line treatment of anovulatory infertility in women with PCOS & 1 & 0.4 \\
\hline First time & 1 & 0.4 \\
\hline Novel & 1 & 0.4 \\
\hline Pharmaceutical property & 75 & 27.7 \\
\hline Pharmacokinetic property & 51 & 18.8 \\
\hline Purest of choice & 1 & 0.4 \\
\hline Safety & 12 & 4.4 \\
\hline Smart gel & 1 & 0.4 \\
\hline Total & 271 & 100.0 \\
\hline
\end{tabular}

Dosage form and regimen noted in only 86 (31.7\%) DPL while in $116(42.8 \%)$ it was missing. There was no mention of side-effects and major adverse drug reactions precautions in $234(86.3 \%)$ DPL. Information about contra-indications and warnings was missing in 236 (87.1\%) DPL. Similarly, 239 (88.2\%) DPL didn't display about major drug interactions involved. In only 227
(83.8\%) DPL name and address of manufacturer or distributor was mentioned while references to scientific

literature as appropriate were mentioned in only 117 (43.2\%) DPL. Claims were also categorized, most of the claims were based on efficacy 107 (39.5\%), pharmaceutical property $75(27.7 \%)$ followed by pharmacokinetic property $51(18.8 \%)$. These claims are 
basically highlighting the superiority of the pharmaceutical product. This is comparable to a similar study by Gurpreet et al where claims related to efficacy were found in $70 \%$ of the brochures. ${ }^{14}$

The present study indicated that the regulatory guidelines were not followed by most of the pharmaceutical companies pertaining to information on adverse effects, the names of ingredients that may cause adverse effects or possible drug interaction and the similar findings have been observed in other studies conducted in India and other developing countries. ${ }^{15}$

\section{Limitations}

Limitations of current study were; small sample size, given the number of drugs marketed. Also, the study was conducted only in a single centre. DPL of ayurvedic/herbal medicines were not analyzed. There is also a need to assess the awareness of the practitioners by intervention study that provides guidance about accurate and ethical information from DPLs.

\section{CONCLUSION}

It was concluded that the drug information provided in the promotional brochures can be incomplete and unreliable. Hence a physician should not rely solely on the DPL provided by medical representatives. All brochures circulated among prescribers must undergo a strict process of assessment regarding information provided, especially related to efficacy and safety. Further advertisements which do not confirm with the standard guidelines should not be allowed to be circulated. Current pilot study is successful in highlighting the areas which need improvement as far as promotional brochures are concerned.

\section{ACKNOWLEDGEMENTS}

Authors would like to thank Mr. Narayana Swamy, for carrying out statistical analysis of the study.

Funding: No funding sources

Conflict of interest: None declared

Ethical approval: The study was approved by the Institutional Ethics Committee

\section{REFERENCES}

1. IFPMA code of practice. Available at: www.ifpma.org/resource-centre/ifpma-code-ofpractice/. Accessed on 20 January 2021.

2. Mikhael EM. Evaluating the reliability and accuracy the promotional brochures for the genetic pharmaceutical companies in Iraq using WHO guidelines. J Pharma Bioall Sci. 2015;7:65-8.
3. Thapa BB. Ethics in promotion of medicine (editorial). Drug Bull Nepal. 2006;18(2):3-4.

4. US promotional spending on prescription drugs. Available at: https://www.cbo.gov/publication/25006. Accessed on 20 January 2021.

5. Lexchin J. Deception by design: pharmaceutical promotion in the third world. Available at: https://repository.library.georgetown.edu/handle/1082 2/879330. Accessed on 20 January 2021.

6. Drug Promotion what we know, what we yet to learn. Available at: https://apps.who.int/iris/handle/ 10665/69177. Accessed on 20 January 2021.

7. Smita NM, Dudhgaonkar S, Bachewar NP. Evaluation of rationality of promotional drug literature using World Health Organization guidelines. Indian J Pharmacol. 2010;42(5):267-72.

8. Jaykaran DS, Yadav P, Kantharia ND. Drug promotional literature distributed by pharmaceutical companies: Do they provide enough information to ascertain their validity?. J Pharmacol Pharmacother. 2011;2(3):192-4.

9. Kakar S, Gautam C, Patel VJ. Drug information sources: Focus on promotional drug literature. JAABMS. 2000;2:8-9.

10. Ethical criteria for medicinal drug promotion. Available at: http://apps.who.int/medicinedocs/ documents/whozip08e/whozip08e.pdf. Accessed on 20 January 2021.

11. OPPI Code of pharmaceutical practices. Available at: http://www.indiaoppi.com/sites/all/themes/oppi/ images/OPPI-Code-ofPharmaceutical-Practices2012.pdf. Accessed on 20 January 2021.

12. Deolekar P, Yadav P, Deolekar S, Deolekar PS. Evaluation of drug promotional literatures as per world health organization criteria. World J Pharm Res, 2019;8(8):842-50.

13. Jadav SS, Dumatar CB, Dikshit RK. Drug promotional literatures (DPLs) evaluation as per world health organization (WHO) criteria. J Appl Pharmaceut Sci. 2014;4:84-8.

14. Randhawa GK, Singh NR, Rai J, Kaur G, Kashyap R. A critical analysis of claims and their authenticity in Indian drug promotional advertisements. Adv Med. 2015;2015:469147.

15. Islam MS, Farah SS. Misleading promotion of drugs in Bangladesh: evidence from drug promotional brochures distributed to general practitioners by the pharmaceutical companies. J Public Health. 2007;29(2):212-3.

Cite this article as: Kudthni RH, Ahmed FZ, Madanna SS, Derangula SSR, Kumar PA. Evaluation of drug promotional literatures in a tertiary care hospital setting in South India. Int J Basic Clin Pharmacol 2021;10:527-31. 